\title{
MAKNA SIMBOL EMOTIKON DALAM KOMUNITAS KASKUS
}

\author{
Alila Pramiyanti*, Maylanny Christin \\ Ilmu Komunikasi Telkom University \\ alilaku@gmail.com
}

\begin{abstract}
ABSTRAK
Simbol atau lambang adalah suatu tanda untuk menunjuk sesuatu berdasarkan kesepakatan bersama. Penelitian ini membahas penggunaan simbol yang berupa emotikon untuk menjelaskan hal-hal yang tidak terwakili karena keterbatasan nada, suara, dan ekspresi yang belum terwakili. Penelitian ini menggunakan semiotika Pierce yang menganalisis emotikon yang ada pada komunitas Kaskus. Penelitian ini menunjukkan emotikon Kaskus memiliki makna untuk menekankan ekspresi, mempertegas emosi, bentuk apresiasi positif, reputasi, sindiran, metafora, serta stereotip. Selain itu, emotikon yang terdapat pada komunitas Kaskus sangat bervariatif dan menampilkan semangat anak muda yang diwakili atribut seperti warna mencolok serta gambar kreatif.
\end{abstract}

Kata kunci: emotikon, Kaskus, komunitas, makna, simbol

\begin{abstract}
A symbol or an emblem is a sign to point at something based on mutual agreement. This study discusses the use of symbols such as emoticons to explain things that are not represented due to the limitations of tone, voice, and expressions. This study analyzes emoticons used in the Kaskus community by using Pierce's semiotics. This study suggests that Kaskus' emoticons have some meanings to emphasize expressions, reinforce emotions, indicate positive appreciations, reputation, satires, metaphors, and stereotypes. In addition, emoticons used in Kaskus community are highly varied and show the spirit of young people, represented by attributes such as bright colors and creative images.
\end{abstract}

Keywords: emoticon, Kaskus, community, meaning, symbol 


\section{PENDAHULUAN}

Kebutuhan informasi yang cepat menjadi alasan mengapa pertumbuhan internet meningkat. Munculnya internet telah membuat banyak perubahan dalam kehidupan manusia. Internet telah mempercepat dan memberikan bentuk baru interaksi manusia melalui pesan instan, forum internet, chatting, jejaring sosial dan komunitas online. Salah satu komunitas online terbesar di Indonesia adalah Kaskus yang berasal dari kata Kasak Kusuk. Kaskus sangat digemari karena kemampuanya dalam mengakomodasi hampir semua kebutuhan, keinginan, dan minat dari para surfer internet.

Komunitas ini menyediakan forum yang membahas segala hal, mulai topik politik yang serius hingga topik yang sangat ringan dan remeh. Komunitas ini juga menyediakan forum jual beli (FJB) yang memungkinkan pengguna internet untuk berjual beli mulai dari barang yang bernilai puluhan ribu hingga tanah yang berharga ratusan juta rupiah.

Emotikon atau simbol khas dalam percakapan jejaring forum internet menempati posisi yang cukup penting dalam proses terjadinya komunikasi di antara para pengguna internet, khususnya anggota jejaring Kaskus. Emotikon dapat menjadi sarana yang efektif untuk menghindari kesalahan interpretasi pesan yang ingin disampaikan oleh para pengguna internet dalam berkomunikasi. Secara sederhana simbol atau lambang adalah suatu tanda yang digunakan untuk menunjuk sesuatu berdasarkan kesepakatan bersama. Pierce menegaskan kita hanya dapat berpikir dengan sarana tanda; tanpa tanda komunikasi tidak dapat dilakukan.

\section{KAJIAN PUSTAKA}

\section{Pengertian Komunikasi}

Komunikasi berasal dari kata bahasa Inggris communication. Jika ditelusuri lebih lanjut, kata ini berakar dari bahasa latin communis yang berarti sama dan dari kata communico, communicare yang berarti "membuat sama" (to make common). Istilah pertama (communis) diyakini sebagai akar atau bentuk dasar terbentuknya kata komunikasi. Komunikasi menyarankan suatu pikiran, suatu makna, suatu persepsi atau suatu pesan yang dianut secara sama (Mulyana, 2007:46).

Komunikasi selalu hadir dalam kehidupan manusia karena merupakan faktor yang sangat penting dan dilakukan dalam berbagai konteks. Komunikasi antarmanusia memiliki fungsi untuk mengekspresikan diri, menjalin hubungan, bersosialisasi, dan lainlain.

Komunikasi merupakan suatu proses simbolik. Menurut Ernst Cassier sebagaimana dikutip Mulyana (2007: 92), manusia memang satu-satunya makhluk yang menggunakan simbol atau lambang. Hal itulah yang membedakannya dengan makhluk lain. Oleh karena itu, manusia disebut sebagai animal symbolicum.

\section{Simbol}

Kata simbol berasal dari bahasa Yunani sym-ballein atau symbolos. Simbol memiliki arti tanda atau ciri yang memberitahukan sesuatu kepada seseorang. Sementara itu, dalam KBBI (2008) simbol atau lambang adalah semacam tanda, lukisan, perkataan, lencana, dan sebagainya yang menyatakan sesuatu atau mengandung maksud tertentu. Simbol adalah bentuk yang menandai sesuatu di luar perwujudan bentuk simbolik itu sendiri. Simbol tidak dapat disikapi secara isolatif, terpisah dari hubungan asosiatifnya dengan simbol lainnya. Simbol atau dalam bahasa komunikasi sering diistilahkan sebagai lambang meliputi kata (pesan verbal), perilaku nonverbal, dan objek yang maknanya disepakati bersama.

Mead seperti dikutip Sobur (2009:163) membedakan simbol signifikan yang merupakan bagian dari dunia makna manusia dengan tanda alami (natural signs) yang merupakan bagian dari dunia fisik. Pertama, simbol digunakan dengan sengaja sebagai sarana komunikasi. Kedua, simbol digunakan secara spontan dalam merespons stimulan. Makna tanda alami ditemukan karena hal ini adalah bagian dari hukum (hubungan sebab-akibat) 
alam, seperti asap yang merupakan tanda alami dari api. Akan tetapi, makna simbol memiliki hubungan kausal dengan apa yang direpresentasikannya. Respons manusia bersifat simbolik, sedangkan respons hewan terutama bersifat alami (otomatis dan spontan).

\section{Emotikon}

Emotikon merupakan akronim dari emotional icon. Asteroff (1987) mendefinisikan emotikon sebagai relational icons, sedangkan Sanderson (1993) menjelaskan emotikon atau smilleys merupakan suatu karakter yang dapat dicari dalam komputer yang digunakan ketika berkomunikasi melalui komputer. Danet, Ruedenberg-Wright, dan Rosenbaum-Tamari (1997) juga menjabarkan emotikon sebagai ikon untuk mengekspresikan emosi atau untuk menandai niat seseorang sebagai hal yang tidak serius. Emotikon yang terkenal adalah senyum, mengedipkan mata, marah, dan kerutan. Sementara Rezabek dan Cochenour (1998) menyatakan bahwa emotikon adalah isyarat visual yang terbentuk dari tipografi simbol biasa yang ketika dibaca terbalik akan mewakili perasaan atau emosi (Walther dan D'Addario, 2001).

Emotikon diciptakan sebagai kompensasi dari ketidakmampuan penyampaian nada suara, ekspresi muka, maupun isyarat atau sikap tubuh dalam komunikasi tertulis. Oleh karena itu, emotikon dapat menjembatani pemisah antara pesan tulisan dengan percakapan tatap muka serta memberikan gambaran kepada pembaca tentang apa yang dimaksudkan oleh penulis melalui tampilan gambar ekspresi wajah. Emotikon biasa digunakan pada teks pesan singkat, e-mail, atau pada forum internet, seperti chat-rooms maupun blog. Pada forum situs, pesan singkat, dan permainan online, teks emotikon sering secara otomatis tergantikan dengan gambar-gambar kecil yang sesuai yang kemudian dinamai emotikon grafis.

Awalnya, gambar emotikon ini cukup sederhana dan hanya mengganti deret karakter yang umum, tetapi seiring berjalannya waktu karakter emotikon ini menjadi semakin rumit. Emotikon yang lebih khusus sering harus me- nggunakan menu khusus. Emotikon juga telah dikembangkan dari kartun pengekspresian wajah yang sederhana menjadi beragam gambar yang diam maupun yang bergerak, penuh animasi, berwarna, dan kadang-kadang disertai dengan suara yang dapat membuat emotikon ini terkesan lebih "hidup".

\section{Semiotika Pierce}

Semiotika dapat dijelaskan sebagai ilmu mengenai tanda. Tanda merupakan istilah yang penggunaannya sangat luas. Dalam Webster Collegiate Dictionary ninth Ed., terdapat tidak kurang dari 20 arti yang berhubungan dengan tanda. Hal ini menjelaskan betapa kompleksnya tanda dan semiotika sebagai ilmu tentang tanda. Charles Sanders Pierce (1834-1914) dan Ferdinand de Saussure (1857-1913) adalah pelopor penggunaan semiotika. Mereka menemukan batu pijakan bagi semiotika walaupun keduanya tidak saling mengenal.

Semiotika melihat tanda sebagai dua sisi uang logam yang tak terpisahkan. Di satu sisi terdapat penanda (signifier) yang dapat diasosiasikan dengan representament dalam semiotika Pierce. Pada sisi lain, terdapat petanda (signified) yang dapat diasosiasikan sebagai interpretant dalam konsep Pierce. Konsep Pierce menjelaskan terdapat relasi antara representamen (hasil representasi) dan interpretant (hasil interpretasi) yang mengakibatkan adanya simbol, indeks, dan ikon (Sobur, 2009:42).

Dalam semiotika, konotasi, dan denotasi juga memiliki makna yang penting. Hal ini berkaitan dengan bagaimana sebuah tanda diinterpretasikan (signified). Makna denotasi dapat dikatakan sebagai makna pertama sedangkan makna konotasi dapat disebut sebagai makna kedua (Wibowo, 2011:17).

\section{METODE PENELITIAN}

Metode yang digunakan adalah analisis isi kualitatif berupa semiotika Pierce. Salah satu prinsip komunikasi adalah komunikasi melibatkan tanda dan kode. Tanda adalah material atau tindakan yang menunjuk pada 
'sesuatu', sementara kode adalah sistem tandatanda yang diorganisasikan dan menentukan bagaimana tanda dihubungkan dengan yang lain. Dengan demikian, pusat perhatian semiotika pada kajian komunikasi adalah menggali apa yang tersembunyi di balik bahasa verbal atau nonverbal. Penelitian ini menganalisis makna simbol emotikon yang sering digunakan dalam komunitas Kaskus.

\section{HASIL}

Kaskus memiliki simbol emosi yang unik. Berikut ini adalah emotikon yang hanya dapat ditemukan dan digunakan di Kaskus serta representament dari emotikon tersebut.

\section{Tabel 1. Representament Simbol Kaskus}

\begin{tabular}{|c|c|c|c|c|c|}
\hline \multirow{2}{*}{ No } & \multirow{2}{*}{ Gambar } & \multirow{2}{*}{$\begin{array}{c}\text { Cara } \\
\text { Pengetikan }\end{array}$} & \multicolumn{3}{|c|}{ Representamen } \\
\hline & & & Ekspresi & Warna & Gambar \\
\hline 1 & & :takut & takut & Biru & $\begin{array}{l}\text { badan bergetar, memperlihatkan } \\
\text { gigi }\end{array}$ \\
\hline 2 & & :repost: & marah & Kuning & $\begin{array}{l}\text { wajah marah dan tangan membawa } \\
\text { tanda dengan tulisan repost. }\end{array}$ \\
\hline 3 & & :ngakak & ketawa & Oranye & gigi besar, mata mengecil \\
\hline 4 & & :ngacir & bahagia & $\begin{array}{l}\text { biru dan merah } \\
\text { muda }\end{array}$ & $\begin{array}{l}\text { laki-laki dan perempuan membawa } \\
\text { bunga pergi naik vespa }\end{array}$ \\
\hline 5 & & :mewek & nangis & Oranye & $\begin{array}{l}\text { mata besar menahan jatuhnya air } \\
\text { mata. }\end{array}$ \\
\hline 6 & & :marah & geram & Merah & $\begin{array}{l}\text { mata merah, mengeluarkan asap, } \\
\text { mulut melengkung ke bawah } \\
\text { dengan gigi-gigi bertaring }\end{array}$ \\
\hline 7 & & :kiss & kasih sayang & Merah muda & $\begin{array}{l}\text { rambut dikuncir kuda, tangan } \\
\text { menutup mulut }\end{array}$ \\
\hline 8 & & :salahkamar & tidak terlihat & Biru & $\begin{array}{l}\text { membuka pintu, dan ada tanda seru } \\
\text { keluar dari pintu. }\end{array}$ \\
\hline 9 & & :kbgt: & mengejek & Kuning & $\begin{array}{l}\text { lidah keluar dengan memikirkan } \\
\text { kaskus banget }\end{array}$ \\
\hline 10 & & :jrb: & teriak & Oranye & $\begin{array}{l}\text { berteriak mengenai imbauan yang } \\
\text { ditulis dengan huruf kapital dengan } \\
\text { tanda seru. }\end{array}$ \\
\hline 11 & & :iloveindonesia & bangga & $\begin{array}{l}\text { abu-Abu } \\
\text {,bendera merah } \\
\text { putih }\end{array}$ & $\begin{array}{l}\text { memegang bendera Indonesia di } \\
\text { tangan kanan dan kiri }\end{array}$ \\
\hline 12 & & :hn & antusias & $\begin{array}{l}\text { biru, latar } \\
\text { bertulisan merah }\end{array}$ & $\begin{array}{l}\text { membaca berita dengan latar } \\
\text { tulisan hot news dalam kotak TV }\end{array}$ \\
\hline 13 & & :cendol & kagum & Biru & $\begin{array}{l}\text { mata ceria sambil tersenyum lebar, } \\
\text { membawa segelas cendol }\end{array}$ \\
\hline 14 & & :cd & $\begin{array}{l}\text { menahan } \\
\text { emosi }\end{array}$ & Kuning & tangan menutup wajah \\
\hline
\end{tabular}




\begin{tabular}{|c|c|c|c|c|c|}
\hline 15 & & :berduka & sedih & Hitam & wajah sedih dengan yang layu \\
\hline 16 & & sup: & senang & Kuning & $\begin{array}{l}\text { gigi mendominasi wajah, dengan } \\
\text { tulisan sundul lagi ah!up!up! diatas } \\
\text { kepala }\end{array}$ \\
\hline 17 & & :sorry & menyesal & Kuning & alis, mata, mulut turun ke bawah \\
\hline 18 & & :selamat & bahagia & Oranye & senyuman lebar, topi ulang tahun \\
\hline 19 & & :request & $\begin{array}{l}\text { menginginka } \\
\mathrm{n} \text { sesuatu }\end{array}$ & abu-Abu & menunjukkan sesuatu \\
\hline 20 & & :recsel & kagum & Oranye & $\begin{array}{l}\text { wajah tersenyum menunjukkan } \\
\text { medali dengan tulisan seller }\end{array}$ \\
\hline 21 & 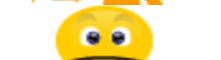 & :nohope & & Kuning & wajah datar \\
\hline 22 & & :ngacir2 & & $\begin{array}{l}\text { biru dan warna } \\
\text { bajaj oranye }\end{array}$ & $\begin{array}{l}\text { supir bajaj dengan menunjukkan } \\
\text { suatu arah }\end{array}$ \\
\hline 23 & & :najis & heran & Hijau & $\begin{array}{l}\text { mulut mengeluarkan sesuatu, bulu } \\
\text { mata panjang, bibir menggunakan } \\
\text { lipstick }\end{array}$ \\
\hline 24 & $\begin{array}{l}\text { MOD! } \\
\text { Need you here! }\end{array}$ & :kacau: & marah besar & merah, & $\begin{array}{l}\text { mulut ditutup tanda } \mathrm{x} \text { dengan } \\
\text { tulisan diatas kepala MOD!NEED } \\
\text { YOU HERE! }\end{array}$ \\
\hline 25 & & $\begin{array}{l}: \mathrm{dp} \text { (disturbing } \\
\text { picture) }\end{array}$ & muntah & Biru & $\begin{array}{l}\text { mengeluarkan sesuatu dari dalam } \\
\text { mulut }\end{array}$ \\
\hline 26 & & :cool & $\begin{array}{l}\text { datar tanpa } \\
\text { emosi }\end{array}$ & Biru & mata redup \\
\hline 27 & & :cekpm & senyum & $\begin{array}{l}\text { biru keabu- } \\
\text { abuan }\end{array}$ & $\begin{array}{l}\text { wajah senyum dengan kotak pos } \\
\text { bertulisan PM (private message) }\end{array}$ \\
\hline 28 & & :bingung & bingung & Kuning & alis ke atas, mata bingung, \\
\hline 29 & & $\begin{array}{l}\text { :betty (beda } \\
\text { tipis) }\end{array}$ & centil & Hijau & mata genit, bibir dower \\
\hline 30 & & :batabig & kesal & Biru & menunjukkan gigi, mata melotot \\
\hline 31 & & :angel & bijak & Merah muda & $\begin{array}{l}\text { perempuan dengan lingkaran emas } \\
\text { diatas kepala dan dua sayap putih }\end{array}$ \\
\hline 32 & & :alay & berlebihan & abu-abu & $\begin{array}{l}\text { bulu mata pangjang pakai } \\
\text { kacamata, bibir dower berlipstick, } \\
\text { menggunakan kalung alay, jari } \\
\text { telunjuk dan kelingking kedua }\end{array}$ \\
\hline
\end{tabular}


tangan menunjuk keatas.

\begin{tabular}{|c|c|c|c|c|}
\hline 33 & :rate5 & bangga & $\begin{array}{l}\text { abu-abu, dengan } \\
\text { bintang emas }\end{array}$ & $\begin{array}{l}\text { memegang tanda jasa dengan lima } \\
\text { bintang }\end{array}$ \\
\hline 34 & :siul & usil & biru muda & mulut mengeluarkan tanda nada \\
\hline 35 & :hammer & kesal & $\begin{array}{l}\text { biru dan palu } \\
\text { coklat }\end{array}$ & kepala dipukul palu \\
\hline 36 & :hoax & genit & Hijau & $\begin{array}{l}\text { mulut bentuk love berlipstick, bulu } \\
\text { mata panjang }\end{array}$ \\
\hline 37 & :thumbup & pujian & Kuning & mengacungkan satu jempol \\
\hline $3 \varepsilon$ & :2thumbup & pujian & Kuning & mengacungkan dua jempol \\
\hline 35 & :shakehand2 & sepakat & biru dan kuning & berjabat tangan \\
\hline 40 & :malu & malu & Kuning & $\begin{array}{l}\text { mata terpejam wajah merona } \\
\text { tersipu malu }\end{array}$ \\
\hline
\end{tabular}

Warna bersangkut paut dengan in- sekunder seperti oranye, hijau, dan ungu. terpretasi dan persepsi. Warna berkembang sesuai dengan berjalannya waktu. Sebagai contoh warna yang dipakai dalam emotikon komunitas Kaskus pada tabel 1 bukan hanya warna primer seperti merah, kuning, biru, namun beralih pada warna sekunder dan tersier. Warna

Warna tersier adalah percampuran antara warna primer dan warna sekunder. Sementara petanda atau interpretant pada emotikon di atas adalah seperti terlihat pada tabel 2 berikut ini.

\section{Tabel 2. Interpretant Emotikon Kaskus}

Interpretant
Bo


4

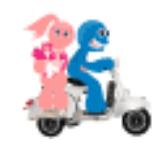

5

6

7

8
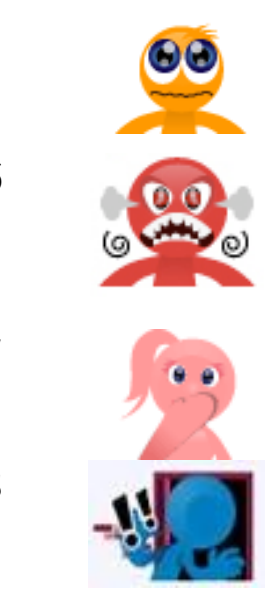

9

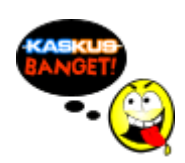

10

11

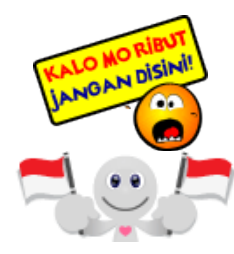

12

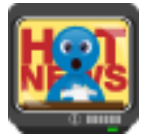

13

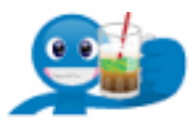

14

Berdasarkan interpretasi asosiasi dan psikologi warna, merah muda identik dengan kasih sayang. Biru termasuk dalam warna primer sedangkan merah muda termasuk ke dalam warna tersier mengendarai vespa warna putih identik dengan anak muda retro yang dinamis pergi membawa bunga, ngacir adalah pergi dengan bersemangat setelah mengejek dan menjahili dalam forum.

Berdasarkan interpretasi asosiasi dan psikologi warna, oranye negatif diasosiasikan dengan kepribadian extrovert. Bola mata besar menahan air mata yang akan jatuh menandakan kesedihan ataupun terharu.

Berdasarkan interpretasi asosiasi dan psikologi warna, merah adalah warna yang membangkitkan gairah, emosi, semangat. Warna merah termasuk ke dalam warna primer. Emotikon ini menunjukkan kekesalan yang sudah memuncak.

Berdasarkan interpretasi asosiasi dan psikologi warna, merah muda yang identik dengan romantisme, kasih sayang gambar ini merepresentasikan perempuan malu tersipu-sipu.

Berdasarkan interpretasi asosiasi dan psikologi warna, ruangan hitam dapat dimaknai sebagai suatu ruang yang penuh tekanan. Kata 'salah kamar' yang digunakan memiliki makna teguran bagi anggota yang bicara out of topic. Jadi ruangan gelap yang akan dimasuki dianggap menekan anggota untuk membicarakan topik yang tidak nyambung.

Berdasarkan interpretasi asosiasi dan psikologi warna, kuning dikaitkan dengan kecerdasan, ide baru, kepercayaan terhadap potensi diri. Lidah keluar dengan memikirkan kaskus banget Hitam Positif melambangkan keabadian yang menjadikan sebuah harapan kelak Kaskus menjadi sebuah komunitas yang abadi

Berdasarkan interpretasi asosiasi dan psikologi warna, oranye lambang persahabatan. Emotikon ini menunjukkan sang penengah jika ada member yang bersitegang.

Berdasarkan interpretasi asosiasi dan psikologi warna abu-abu warna yang paling netral dianggap aman dan sopan. Bendera merah putih yang digenggam di kedua tangan menekankan rasa bangga menjadi bangsa Indonesia.

Berdasarkan interpretasi asosiasi dan psikologi warna, biru positif memiliki arti intelegensi tinggi, produktif. Emotikon ini menunjukkan anggota Kaskus saling berbagi pengetahuan dan tren terbaru yang sedang hangat dibicarkan.

Berdasarkan interpretasi asosiasi dan psikologi warna, biru positif identik dengan kebenaran, kontemplatif, damai. Emotikon yang dipresentasikan dengan mata dan mulut terbuka lebar menggambarkan ketertarikan juga kekaguman. Segelas cendol di kaskus merupakan sebutan reputasi atau istilahnya GRP (good reputation point). Semakin banyak GRP yang didapat maka ikon hijau di ID user tersebut akan semakin banyak dan hal itu menandakan user tersebut semakin dipercaya oleh user lain baik itu reputasi jualannya di FJB atau sering membagikan sharing dan hal-hal yang gratis di forum Kaskus.

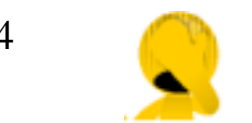

Berdasarkan interpretasi asosiasi dan psikologi warna, kuning negatif menunjukkan sikap sinis. Emotikon ini menunjukan orang yang menutup muka karena kebosanan, ketidaktertarikan, dan identik dengan istilah 'cape deh'. Cape (capek) di sini bukan berarti lelah secara fisik namun lelah secara psikis sambil menahan amarah. 


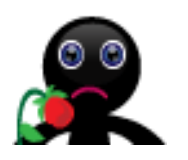

16

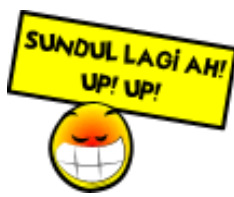

17

18

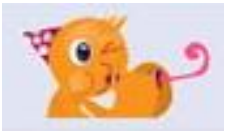

19

20

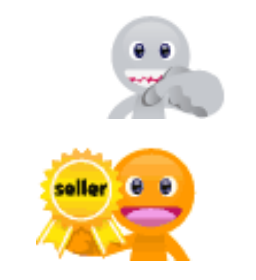

21

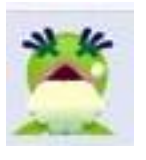

24

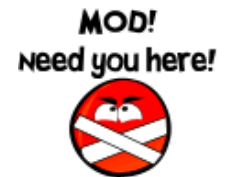

25
Berdasarkan interpretasi asosiasi dan psikologi warna hitam, sebagai warna yang tertua (gelap) dengan sendirinya menjadi lambang untuk sifat gulita dan kegelapan (juga dalam hal emosi). Warna hitam adalah warna subractive yang merupakan warna sekunder dari warna aditive. Gambar ini menunjukan kesedihan yang ditunjukan dengan posisi bibir mengarah ke bawah dan tanaman yang melayu.

Berdasarkan interpretasi asosiasi dan psikologi warna, kuning merupakan warna dengan efek yang kuat sehingga secara psikologis warna ini sangat efektif diterapkan pada hal-hal yang membutuhkan motivasi dan menaikkan mood. Gigi mendominasi wajah, dengan tulisan sundul lagi ah!up!up! di atas kepala dimaksudkan agar sebuah isu menjadi hot topic.

Berdasarkan interpretasi asosiasi dan psikologi warna, kuning positif memiliki arti jujur. Alis, mata, mulut turun ke bawah, mata memelas merupakan bentuk ekspresi pernyataan maaf. Hal ini menunjukkan kejujuran untuk mengakui kesalahan.

Berdasarkan interpretasi asosiasi dan psikologi warna, oranye dapat memancarkan keceriaan termasuk ke dalam warna sekunder. Emotikon ini dipresentasikan dengan topi ulang tahun yang menyatakan selamat. Emotikon ini tidak hanya digunakan untuk menyatakan selamat ulang tahun saja namun juga untuk keberhasilan atau kesuksesan lainnya.

Berdasarkan interpretasi asosiasi dan psikologi warna, abu-abu warna yang paling netral dianggap aman dan sopan. Pernyataan permintaan terhadap sesuatu dengan emotikon telunjuk menunjuk ke arah depan.

Berdasarkan interpretasi asosiasi dan psikologi warna, oranye menebarkan energi, menghangatkan termasuk ke dalam warna sekunder. Emotikon ini menyatakan kekaguman yang ditunjukan dengan memperlihatkan sebuah penghargaan berupa mendali. Hal ini menujukkan bentuk apresiasi pada anggota yang dianggap kredibel, menyenangkan, memuaskan, dan lainnya.

Berdasarkan interpretasi asosiasi dan psikologi warna, kuning negatif menunjukkan sikap sinis. Emotikon ini menyatakan tidak terlalu berharap tentang suatu keadaan.

Berdasarkan interpretasi asosiasi dan psikologi warna, bajaj yang terdiri dari warna hitam yang melambangkan keabadian dan oranye yang menyatakan keceriaan. Emotikon ini menyatakan pergi ke suatu tempat.

Berdasarkan interpretasi asosiasi dan psikologi warna, hijau negatif melambangkan pahit. Emotikon ini mewakili kata najis. Hal ini berarti topik threads merupakan topik yang menjijikkan sebagaimana halnya kategori najis. Bulu mata panjang dan lipstick dapat diasosiakan sebagai perempuan.

Berdasarkan interpretasi asosiasi dan psikologi warna, merah bersifat menaklukkan, ekspansif (meluas), dominan (berkuasa), aktif, dan vital (hidup). Emotikon ini menunjukkan sebuah kekacauan yang terjadi di dalam threads, dan menginginkan agar ada moderator yang menyelesaikan (MOD! NEED YOU HERE)

Berdasarkan interpretasi asosiasi dan psikologi warna, biru negatif memiliki sifat racun. Racun merupakan zat yang harus dikeluarkan dari tubuh. Emotikon ini memiliki makna bahwa disturbing picture (gambar-gambar yang mengganggu) sebagai racun yang tidak seharusnya berada dalam threads Kaskus. 
26

27

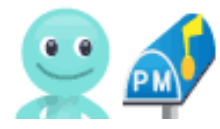

28

29

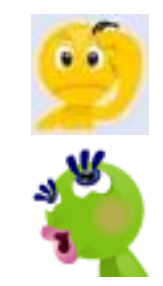

30

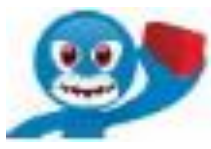

31

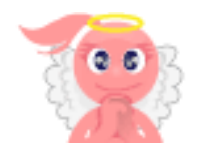

32

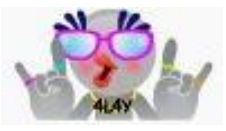

33

34

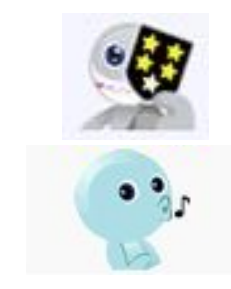

35

36

37
Berdasarkan interpretasi asosiasi dan psikologi warna, biru negatif dapat melambangkan sikap egosentris. Emotikon ini mewakili ungkapan 'cool' yang memiliki arti ketidakpedulian dan tingkat ke'aku'an yang tinggi.

Berdasarkan interpretasi asosiasi dan psikologi warna biru keabu-abuan kerap dipakai untuk hal-hal yang melibatkan teknologi tinggi. Emotikon ini digunakan untuk menyatakan hal-hal yang sifatnya pribadi harap dikonfirmasi secara pribadi (personal message)

Berdasarkan interpretasi asosiasi dan psikologi warna kuning negatif mencerminkan sikap sinis, termasuk kedalam warna primer. Emotikon ini menunjukkan kebingungan ataupun mempertanyakan sesuatu.

Berdasarkan interpretasi asosiasi dan psikologi warna, hijau muda berkesan segar, ringan, dan menyenangkan. Emotikon ini digunakan untuk menunjukkan perbedaan yang sangat sedikit (tipis). Perbedaan tersebut dapat berupa perbedaan harga ataupun pendapat. Bulu mata panjang dan lipstik dapat diasosiasikan sebagai perempuan.

Berdasarkan interpretasi asosiasi dan psikologi warna biru sebagai warna yang menimbulkan kesan dalamnya sesuatu, sifat yang tak terhingga dan transenden, disamping itu memiliki sifat tantangan. Emotikon ini digunakan untuk menyatakan sesuatu yang sifatnya mengesalkan.

Berdasarkan interpretasi asosiasi dan psikologi, warna merah muda menciptakan perasaan lembut dan bebas. Perempuan dengan lingkaran emas diatas kepala dan dua sayap. Emotikon Angel (malaikat) digunakan untuk menunjukan seseorang yang memberi nasihat, katakata bijak, kutipan motivasi.

Berdasarkan interpretasi asosiasi dan psikologi warna, abu-abu bersifat netral. Oleh karena itu, orang bewarna abu menggunakan kalung, kacamata, dan cincin. Emotikon ini menunjukkan hal yang berlebihan. Bulu mata panjang, lipstik, perona pipi, kacamata, kalung dan cincin dapat diasosiakan sebagai perempuan.

Berdasarkan interpretasi asosiasi dan psikologi warna, abu-abu, dengan bintang emas. Emotikon ini menunjukkan apresiasi pada topik yang menarik.

Berdasarkan interpretasi asosiasi dan psikologi warna, biru muda diasosiakan sebagai sesuatu yang bersifat dingin. Nada lagu yang keluar dari mulut bukan berarti emotikon ini menunjukkan rasa bahagia. Emotikon ini menunjukkan seseorang yang bersifat dingin/acuh dan tidak menggubris hal lain.

Berdasarkan interpretasi asosiasi dan psikologi warna, biru negatif dapat berarti emosional. Pada emotikon ini rasa marah dapat mengakibatkan anggota ingin memukul kepala anggota lain yang dirasakan sebagi pengacau.

Berdasarkan interpretasi asosiasi dan psikologi warna, hijau negatif berarti pahit. Hal ini tidakk menunjukkan sesuatu yang menjijikkan, menggelikan, sekedar isu karena biasa hal-hal yang disampaikan oleh karakter seperti dianggap sebuah gosip atau isu semata. Berita hoax (bohong) yang kebenarannya tidak dapat dipertanggungjawabkan tersebut ditandai dengan cairan putih yang keluar dari mulut. Bulu mata panjang dan lipstik dapat diasosiasikan sebagai perempuan.

Berdasarkan interpretasi asosiasi dan psikologi warna, kuning positif berarti positif. Acungan jempol menandakan suatu pujian atas sebuah 
38

39

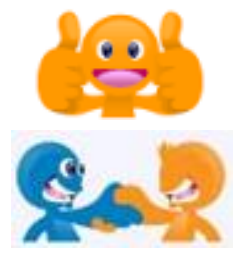

40

\section{prestasi.}

Berdasarkan interpretasi asosiasi dan psikologi warna, kuning positif berarti positif. Acungan dua jempol menandakan suatu pujian atas sebuah prestasi yang luar biasa.

Berdasarkan interpretasi asosiasi dan psikologi warna, biru dan kuning dapat diartikan kepercayaan. Saling berjabat tangan menunjukkan saling percaya serta sepakat terhadap suatu hal.

Berdasarkan interpretasi asosiasi dan psikologi warna, kuning adalah jujur. Emotikon ini mengungkapkan secara jujur perasaan malu.

\section{PEMBAHASAN}

Menurut Walther yang dikutip oleh Baldwin (2004:247), umpan balik dalam CMC dapat mengarah pada "perputaran intensif" konfirmasi pesan dari tiap perilaku komunikasi dapat menguatkan perilaku masing-masing. Walther juga mengemukakan, "komunikasi hyperpersonal pada komunikasi online lebih membangkitkan hasrat untuk bersosialisasi dan lebih intim daripada komunikasi tatap muka (face to face)." Walter menggunakan pendekatan hyperpersonal communication untuk memberi label pada aktivitas melalui CMC yang lebih intim daripada hubungan romantis atau persahabatan yang berpasangan secara fisik.

Sementara pakar computer mediated communication Joseph Walther dan Malcolm Parks seperti dikutip oleh Knapp \& Daly, 2002:105) menguraikan terdapat beberapa perspektif dalam berinteraksi melalui media online, di antaranya perspektif interpersonal. Perspektif ini mengacu pada adanya inovasi metode menyampaikan konten emosi dalam pesan mereka dengan menggunakan emotikon. Ada empat bentuk emotikon yaitu bentuk verbal, deskripsi aktivitas fisik, stres atau penekanan, dan smiles.

Emotikon sering digunakan dalam chatting. Komunikasi melalui chatting memiliki kekhususan terutama karena perkembangan teknologi. Dengan demikian, dalam chatting misalnya, para pengguna dapat meningkatkan keefektifan pesan komunikasi dengan mendayagunakan emotikon untuk membantu mengekspresikan perasaan serta teks dan grafis sehingga keefektifan dapat mengimbangi komunikasi yang diselenggarakan secara tatap muka (Walther, dalam Baldwin, 2004:247).

Kaskus sebagai sebuah komunitas online memiliki beragam forum yang dapat menjadi sarana chatting bagi para anggota. Seperti yang telah diuraikan pada tabel 1 dan 2 bahwa emotikon pada Kaskus memiliki makna yang beragam. Berikut kategorisasi yang dapat diuraikan dari analisis semiotika pada emotikon Kaskus:

1. Penekanan ekspresi

Manusia tidak dapat lepas dari komunikasi nonverbal. Salah satu komunikasi nonvebal adalah ekspresi wajah. Bahkan dalam komunikasi dunia maya pun, manusia selalu mencoba membuat simbol yang merupakan penguatan dan penekanan ekspresi. Pada emotikon Kaskus yang dapat dikategorikan sebagai penekanan ekspresi adalah:

Tabel 3. Penekanan Ekspresi

\begin{tabular}{ccc} 
No & Gambar & Ekspresi \\
\hline 1 & 00 & takut
\end{tabular}




2

2

3

4

2. Mempertegas perasaan

Manusia memerlukan hubungan antarpribadi terutama untuk dua hal yaitu: perasaan (attachment) dan ketergantungan (dependency). Perasaan mengacu pada emosional secara intensif sementara ketergantungan mengacu

\section{ngakak \\ tangis \\ malu}

pada perilaku antarpribadi (Sendjaja, 1994:77). Emotikon berfungsi untuk mempertegas perasaan dalam hubungannya dengan komunikasi. Berikut contoh emotikon yang berfungsi untuk mempertegas perasaan diantaranya:

Tabel 4. Mempertegas Perasaan

\begin{tabular}{lll} 
No & \multicolumn{1}{c}{ Perasaan } \\
\hline 1
\end{tabular}

3. Apresiasi positif

untung rugi dalam komunikasi tidak

Rolof sebagaimana dikutip oleh Sendjaja (1994: 82) mengungkapkan perhitungan antara ganjaran dan upaya berarti bahwa setiap orang saling mengeksploitasi melainkan setiap orang 
akan memilih sesuatu yang menghasilkan bagi dirinya.

Apresiasi positif adalah salah satu bentuk keuntungan yang dapat mempertahankan sebuah komunikasi yang menyenangkan. Berikut lambang apresiasi positif yang terdapat pada komunitas Kaskus diantaranya:

Tabel 5. Apresiasi Positif

\begin{tabular}{lll}
\hline No & \multicolumn{1}{c}{ Apresiasi } \\
\hline 1 & memberi dukungan \\
\hline
\end{tabular}

4. Reputasi

Reputasi merupakan gambaran mintaan dan harapan konsumen. mengenai persepsi tentang seberapa baik penjual atau perusahaan memberikan respon dalam memenuhi perMelalui emotikon berikut ini, Kaskus mencoba membangun reputasi para anggota atau penjual:

Tabel 6. Reputasi

\begin{tabular}{ccl}
\hline No & Gambar & \multicolumn{1}{c}{ Reputasi } \\
\hline 1 & seller yang kredibel \\
2 & topik/threads/produk yang direkomendasikan
\end{tabular}


5. Sindiran

Interaksi dalam komunikasi kelompok merupakan faktor yang sangat penting karena melalui interaksi inilah kita dapat melihat perbedaan antarkelompok. Mereka dapat dikatakan satu kelompok jika dapat mempertukarkan pesan antara yang satu dengan yang lainnya.
Dalam hal sindiran, Adler dan Rodman (dalam Sendjaja, 1994:93) mengemukakan sepanjang setiap anggota mampu mengenal dan memberi reaksi wajar kepada anggota lain atau setiap anggota mampu melihat dan mendengar anggota lain secara wajar maka anggota kelompok tersebut dapat mewujudkan satu atau lebih tujuannya.

Tabel. 7 Sindiran

\begin{tabular}{cc} 
Sindiran \\
\hline 1
\end{tabular}

6. Metafora

Dapat dibayangkan bagaimana bagian besar dibentuk dari pola bahasa kelompoknya. Secara tidak sadar metaseseorang menyesuaikan diri dengan realitas tanpa menggunakan budaya dan fora yang dipilih dipengaruhi interbahasa. Kenyataannya dunia nyata sepretasi sebuah komunitas.

Tabel 6. Metafora

\begin{tabular}{lll}
\hline No & Metafora \\
\hline 1 & Bespa = retro \\
& Kajaj = ngebut \\
&
\end{tabular}




Cape deh = menahan kesal
Muntah = najis
Muntah = jijik dengan disturbing picture

7. Stereotip

Samovar \& Jain sebagaimana dikutip Sendjaja, 1994:315) mengemukakan empat dimensi stereotip, yaitu arah menunjukkan penilaian positif atau 132egative. Intensitas menunjukan kekuatan dan keyakinan dari suatu stereotip, sedangkan ketepatan dan isi menunjukkan sifat khusus suatu kelompok.

Tabel 7. Stereotip

\begin{tabular}{cll}
\hline No & Gambar & \multicolumn{1}{c}{ Stereotip } \\
\hline 1 & & Perempuan centil \\
2 & & $\begin{array}{l}\text { Perempuan yang dandan } \\
\text { berlebihan }\end{array}$
\end{tabular}




\section{SIMPULAN}

Emotikon sebagai budaya komunikasi jika dilihat dari segi penggunaan warna, simbol dalam karakternya menunjukkan setiap emotikon mewakili ekspresi yang kompleks. Pemilihan warna emotikon telah sesuai dengan teori psikologi warna dalam psikologi persepsi. Pengirim pesan dapat menggunakan emotikon untuk menggambarkan emosinya. Emotikon dapat mempertegas emosi yang ingin disampaikan melalui pesan jika penggunaan kata dan tanda baca tidak cukup untuk memperlihatkan maksud pesannya.

Pada komunitas Kaskus ditemukan beberapa kategori emotikon yaitu emotikon untuk menekankan ekspresi, mempertegas emosi, bentuk apresiasi positif, reputasi, sindiran, metafora, serta stereotip. Emotikon ini mayoritas merepresentasikan kebebasan berekspresi, sifat humoris, keakraban, loyalitas serta nasionalisme yang terbangun dalam komunitas Kaskus. Selain itu, pada umumnya emotikon yang digunakan dan ditampilkan ingin memperlihatkan kreativitas para anggota, yang sebagian besar adalah remaja dewasa, yang memiliki motivasi untuk berkreasi.

\section{DAFTAR PUSTAKA}

Baldwin, John R, Perry, S.D \& Moffit, M.A. (2004). Communication theories for everyday life. Boston: Pearson Education INC.

Berger, Arthur Asa. (2005). Tanda-tanda dalam kebudayaan kontemporer. Yogyakarta: Tiara Wacana.

Cangara, Hafied. (2000). Pengantar ilmu komunikasi. Jakarta: Grafindo.

Danesi, Marcel. (2010). Pesan, tanda dan makna. Yogyakarta: Jalasutra.

, Marcel. (2010). Pengantar memahami semiotika media. Yogyakarta: Jalasutra.

Dameria, Anne. (2007). Color basic: panduan dasar warna untuk desainer \& industry. Jakarta: Link and Match Graphic.
Effendy, Onong. (2000). Ilmu teori dan filsafat komunikasi. Bandung: Citra Aditya Bakti.

Knapp, L. Mark \& Daly, A. John. (2002). Handbook of interpersonal communication $\left(3^{\text {rd }}\right.$ ed.). London: Sage Publication.

Liliweri, Alo. (1991). Memahami peran komunikasi massa dalam masyarakat. Bandung: Penerbit PT Citra Aditya Bakti.

Moleong, Alex. (2002). Metode penelitian kualitatif. Bandung: Remaja Rosda Karya.

Mulyana, Deddy. (2007). Komunikasi suatu pengantar. Bandung: Remaja Rosda Karya.

Murphy, John and Michael Rowe. (1998). How to design trademarks and logos. Ohio: North Light Book.

Pilliang, Yasraf A. (2007). Bahan-bahan kuliah semiotika. (Tidak dipublikasikan).

Rakhmat, Jalaluddin. Pramiyanti, Alila \& Maylannya, Christin. (2012). Komunikasi budaya dan jurnalisme warga. Penerbit Alaf Riau.

Sendjaja, Djuarsa. (1994). Teori komunikasi. Jakarta : Universitas Terbuka

Sobur, Alex. (2009). Semiotika komunikasi. Bandung: Remaja Karya Rosdakarya.

Tinarbuko, Sumbo. (2009) Semiotika komunikasi visual. Yogyakarta : Jalasutra.

Vihma, Susann \& Vakeva, Seppo. (2009). Semiotika visual dan semantika produk. Yogyakarta: Jalasutra.

Walther, Joseph B. and Kyle P. D'Addario. (2001). The Impacts of emoticons on Message Interpretation. In computer mediated communication. Social science computer review. p 19: 324.

Wibowo, Indiwan Seto Wahyu. (2011). Semiotika komunikasi. Jakarta: Mitra Wacana Media

Sumber Online

http://support.kaskus.co.id/kamuskaskus/kamus_kaskus.html\#content 